\title{
The effect of Tibial Tuberosity Advancement on Patellar tendon force in Canine Stifle Joint under Caudal Femoral Drawer
}

\author{
Efecto del Avance de la Tuberosidad Tibial (ATT) sobre la fuerza del tendon Patelar en \\ Articulación de Rodilla Canina bajo Fuerza Femoral Caudal
}

\author{
Elsa Pérez-Guindal* iD and Marta Musté-Rodríguez iD \\ Department of Strength of Materials and Engineering Structures, Universidad Politécnica de Cataluña (EPSEVG-UPC). \\ Barcelona, Spain. *Email: elsa.perez@upc.edu
}

\begin{abstract}
The Tibial Tuberosity Advancement (TTA) surgical technique is used in veterinary surgery to limit cranial tibial translation during canine gait, lengthening the lever arm of the quadriceps in Anterior Cruciate Ligament-deficient (ACL-deficient) stifle joints. It is know that after TTA, the patellofemoral pressure decreases, but the Patellar Tendon (PT) behavior has not been observed experimentally yet. This study measures the PT force under caudal femoral drawer at knee flexion angles from $135^{\circ}$ to $90^{\circ}$ in intact and pathological knee to asses the effect of TTA on the tendon. Five fresh cadaveric adult canine stifle joint were tested in an apparatus in which muscle forces of the canine hind limb were simulated. Each knee was tested in three different conditions: intact, ACL-deficient and with TTA. PT force was measured using a electrical transducer. The greater the joint flexion angles, the greater the PT force. The knee average force of the five specimens in $90^{\circ}$ flexion were $28.4 \pm 3.2$ Newtons $(\mathrm{N})$ for the intact, $28.2 \pm 3.4 \mathrm{~N}$ for the ACL-deficient and $24.9 \pm 2 \mathrm{~N}$ for the TTA knee, which decreased compared to the healthy knee, so TTA generates a loosening of the PT force. The PT force showed a fast rate of change in the operated knee because of a shift in the pattern of knee flexion, so the biomechanics of the entire joint could be influenced by the TTA technique.
\end{abstract}

Key words: Tibial tuberosity advancement; patellar tendon; force; trauma; canine stifle joint

\section{RESUMEN}

La técnica quirúrgica de avance de la tuberosidad tibial (ATT) es usada en cirugía veterinaria para limitar la translación craneal de la tibia durante la marcha canina, alargando el brazo de palanca del cuádriceps, en articulaciones de rodilla con ligamento cruzado anterior (LCA) deficiente. Es conocido que después a la intervención de la ATT, la presión patelofemoral disminuye, pero el comportamiento del Tendón Patelar (TP) aún no ha sido observado bajo experimentación. Este estudio mide la fuerza del TP bajo una fuerza femoral caudal a unos ángulos de flexión de la rodilla de $135^{\circ}$ a $90^{\circ}$ en rodilla intacta y dañada para determinar el efecto de la ATT sobre el tendón. Cinco articulaciones de rodilla canina refrigeradas fueron ensayadas en un banco de ensayos, en el cual se simularon las fuerzas musculares de la extremidad trasera canina. Cada rodilla fue probada en tres condiciones: intacta, con LCA deficiente y con la ATT. La fuerza del TP se midió usando transductores eléctricos. A mayores ángulos de flexión, mayor fue la fuerza sobre el TP. Las fuerzas medias de las rodillas en los cinco especímenes en flexión de $90^{\circ}$ fueron, 28,4 $\pm 3,2$ Newtons (N) para la intacta, 28,2 $\pm 3,4 \mathrm{~N}$ para el LCA deficiente y 24,9 \pm 2 $\mathrm{N}$ para la ATT, la cual disminuye comparada con la rodilla sana, lo que muestra que la TTA genera un aflojamiento en la fuerza del TP. La fuerza del TP tiene un porcentaje de cambio mayor en la rodilla con la ATT, debido a cambios en el comportamiento de flexión de la rodilla, por lo que la biomecánica de la articulación al completo podría estar influenciada por dicha técnica.

Palabras clave: Avance de la tuberosidad tibial; tendón patelar; fuerza; trauma; articulación canina 


\section{INTRODUCTION}

Tibial tuberosity advancement (TTA) surgical technique is used successfully to repair the anterior cruciate ligament (ACL)-deficient stifle, one of the most common problem in orthopedics [3, 7]. Anterior displacement of the tibial tubercle was recommended in humans by Maquet to reduce pressure and pain in the patellofemoral (PF) joint in patients with osteoarthritis [10]. In veterinary surgery, the TTA is used to limit cranial tibial translation (CTT) during canine gait, lengthening the lever arm of the quadriceps in ACL-deficient stifle joints $[12,18]$. There are several studies that support the theoretical foundations of TTA [1, 5, 9, 11], using in vitro models that measure the CTT.

A decrease in retropatellar pressure after TTA has recently been demonstrated experimentally in the dog (canis lupus familiaris) [4]. Another recent study evaluated the effects of TTA on the entire knee joint biomechanics by a finite element model [17]. It found that PF contact force increased with flexion and these contact force values were smaller with an advance of 2.5 centimetres $(\mathrm{cm})$. The study also found that not only PF joint, but biomechanics of the femorotibial (FT) joint were significantly influenced by tibial tubercle elevation. Previous investigations focused on the effect of TTA on contact pressure at the PF and FT joint [8], but direct measurements on patellar tendon (PT) force have not been obtained experimentally in dogs.

The aim of this investigation was to measure the PT force under caudal femoral drawer at flexion angles from $135^{\circ}$ to $90^{\circ}$, and determine the effect of TTA on PT structure and the possible effects on TF joint biomechanics. An unconstrained canine stifle joint was tested in vitro in three different conditions: intact knee, ACL-deficient knee and knee with TTA. PT force was measured using electrical extensometry. Based on previous literature, PF forces increase with the knee in flexion and the values decrease with TTA, so it was hypothesized that PT force behaves similarly. It was expected that the PT force increases with flexion and that the TTA repair technique for ACL-deficient knees reduces the PT force.

\section{MATERIALS AND METHODS}

\section{Specimen preparation}

Five fresh cadaveric right canine knees from adult dogs between 25 to 35 kilograms $(\mathrm{kg})$ body weight were used for this study. The posterior extremity specimens were extracted preserving the femoral head, while the tibia was sectioned at its distal third. All muscular structures were excluded, and the extremities were deepfrozen at $-30^{\circ} \mathrm{C}$ immediately afterwards. Initial position of the knee was at an extension angle of $135^{\circ}$, when CTT occurs during canine gait $[2,6,15]$. Muscle forces of the canine hind limb in this position were simulated in accordance with a mathematical model [16]. Since the trials were performed on specimens free of muscles and tissues, a reduction factor was applied.

A variable force spring attached to the proximal end of the femur and the top of the patella was used to play the role of the extensor muscles (FIGS. 1 and 2). The spring was pre-stressed with a force corresponding to $48 \%$ of the dog's weight. To recreate the flexor muscles, mostly attached to the Achilles calcaneus tendon, it was used a constant weight provided by thin plastic cords that were anchored to the supracondylar tuberosities of the femur with two 3.5 milimeters $(\mathrm{mm})$ threaded screws. The cords ran parallel to the tibia towards the heel and passed through a pulley system. The recreated muscle was the Gastrocnemius, the bulkier muscle with its lateral and medial heads, contributing $29.09 \%$ of the specimen's weight (FIG. 1).

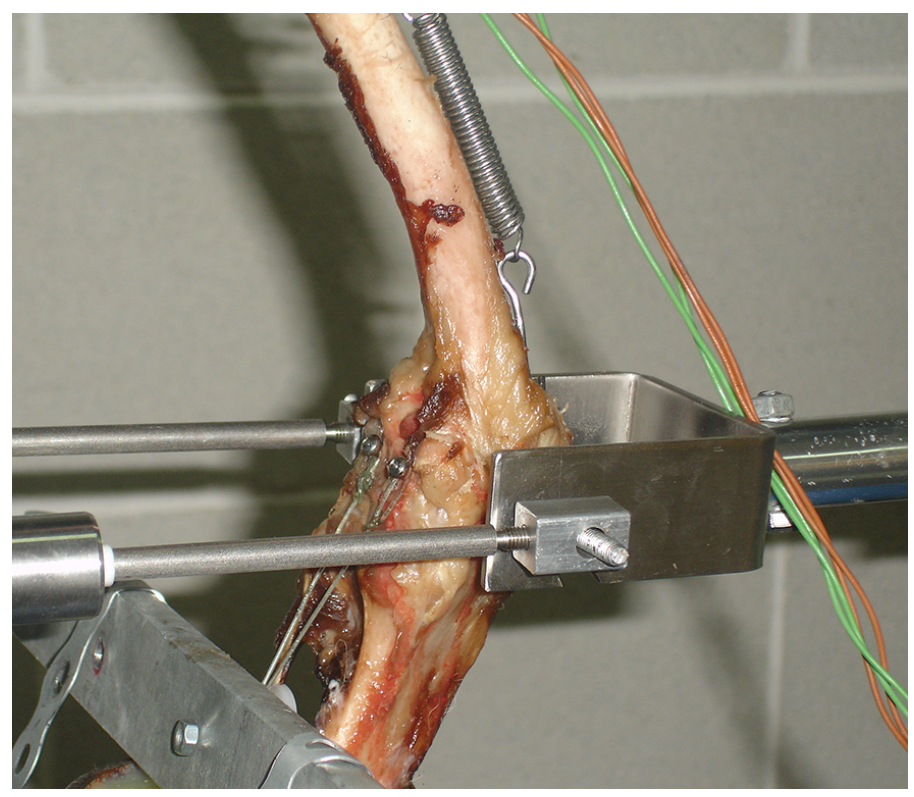

FIGURE 1. Testing bench with specimen and musculature simulators subjected to the caudal femoral force system at a flexion angle

\section{Material-testing machine measurements}

The knee specimens were fixed to an apparatus designed and constructed in the laboratory. The distal end of the tibia-fibula of each specimen was introduced in a container with a high mechanical strength composite to ensure their embedding. The tibia was bent 30 degrees forward to simulate its position during canine gait. The container with the tibia was placed on the testing bench mounting plate with four M6 screws (FIG. 2). In order to produce the caudal femoral drawer, the distal end of the femur was perforated using an M5 threaded rod at the top height of the condyles, and a metal bar was inserted through the holes. A 3-mm steel sheet adaptor was fixed on the metal bar to which the force sensor was connected. The sensor, in turn, was connected to a horizontal force applicator metal wire through a pulley (FIG. 1). The spring force simulating the extensor muscles held the limb in extension. The upper stop limited the angle of the limb to 135 degrees. The joint was left free for the rest of the knee movements, so when the shear force was applied the knee flexed from the $135^{\circ}$ to $90^{\circ}$.

\section{Measuring systems}

The devices measuring tibiofemoral shear force and PT force were force sensors based on electromechanical transducers, formed by a tension load cell. The device which measure PT was fixed between the spring and the patella (FIG. 2), so it measured the quadriceps tendon (QT) force. Using a correlation factor, the QT 


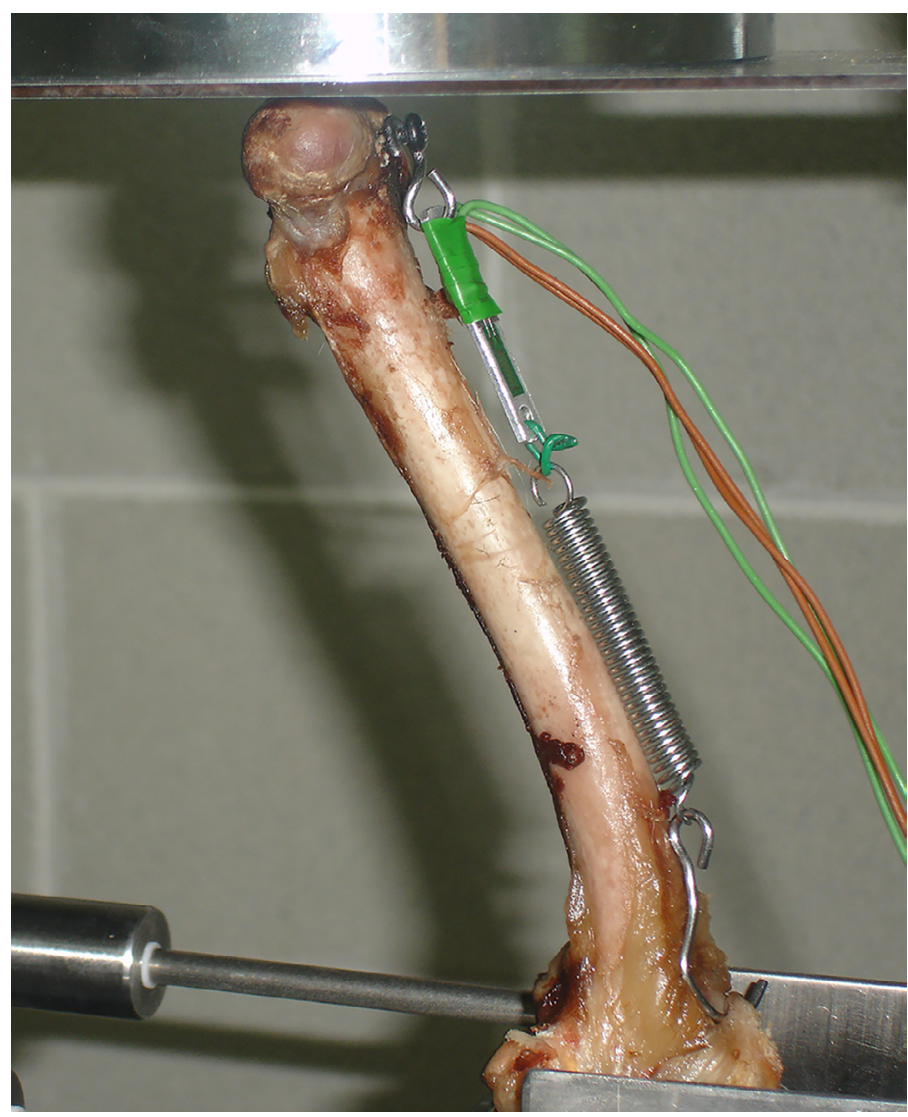

FIGURE 2. Quadriceps tendon force measuring transducer

force was transformed into PT force. Nisell [14] observed that the behavior of both tendons was similar, and that the patellar tendon was $25-30 \%$ thinner and narrower than the quadriceps tendon. The forces in these tendons at knee angles from $120^{\circ}$ to $60^{\circ}$ flexion had a relation (PT/QT) of about $0.70-0.80$ [14]. For canine knees a relation force of $\mathrm{QT} / \mathrm{PT}=1.2$ was applied, considering that the cross section area between both tendons is less different than in humans.

\section{Transducer}

The electrical data were captured and processed by the hardware, which included a multiplexer and a data acquisition card. The multiplexer captured the analogue inputs from all the measuring devices in reading channels. The data acquisition card, converted the analogue data into digital data in the PC. Finally, the data were managed by a software designed using the Laboratory Virtual Instrument Engineering Workbench (LabView) Management Program. This program was responsible for the reading management of all channels on the acquisition card, and for displaying and saving all the generated data in files.

\section{Testing protocol}

The first experiment was performed with the intact stifle joint. The specimen was placed on the testing bench and fixed at an angle of $135^{\circ}$. A tangential force was applied of up to 200 Newtons (N). The knee flexed up to a $90^{\circ}$ position, which was measured with a goniometer. The shear and PT force were registered during flexion.
Later, the ACL was sectioned and the trial was repeated with the same knee. The third experiment was performed after applying the TTA technique with surgical instruments in the laboratory. An advance of $9.0 \mathrm{~mm}$ was applied to all specimens, as described in the TTA technique by Montavon and his colleagues [13]. A device for advancing the tibial tuberosity made of a 316LVM alloy of stainless steel plate of $1 \mathrm{~mm}$ thick was used.

\section{Variable issues}

When the caudal femoral force was applied, the knee flexed from $135^{\circ}$ to $90^{\circ}$ flexion angles. Since the trial was aimed to assess the PT behavior under CTT during flexion, the knee was left free for this movement. But only the first and the last angle positions, which could be matched with the PT force value, were measured. The rest of the angles within the range didn't have a force exact value assigned.

\section{Statistics}

A one way analysis of variance ANOVA with five specimens was used to compare changes in PT force between intact, ACL-deficient knee and TTA surgery. The confidence limits were 95 per cent. AP value of 0.15 was obtained, so no statistical significant difference between the three groups was observed. This happened because there were no differences between intact and ACL-deficient knees. Thus, another analysis between intact and TTA knees was carried out. A P value of 0.07 was obtained and, therefore, the conclusion was that the values depended more on whether the knee was intact or repaired with TTA.

\section{RESULTS AND DISCUSSION}

Patellar tendon forces were measured using a tension load cell. A transducer that measured the spring force which simulated the quadriceps muscle. Because of the high sensitivity of the electromechanical transducers, large amounts of data per second were gathered and highly accurate curves were developed. One of the disadvantages of strain gauges was their sensitivity to temperature and moisture, so the trials were performed under controlled environmental conditions.

Figures from 3 to 7 show the relationship between shear and PT force in each specimen. TABLE I shows the PT force values at 90 degrees angle flexion, when the values were maximum and stabilized. The TABLE I also shows the deviation of ACL-deficient and TTA over the intact knee.

PT behavior tests under cranial shear force showed the same behavior. PT force increased with joint flexion angles from $135^{\circ}$ to $90^{\circ}$. The first value in all the specimens of $12.3 \mathrm{~N}$ was the pre-tension in the muscle simulator spring.

The average $\mathrm{PT}$ forces of the five specimens in $90^{\circ}$ flexion were $28.4 \pm 3.2 \mathrm{~N}$ for the intact, $28.2 \pm 3.4 \mathrm{~N}$ for the $\mathrm{ACL}$-deficient knee and $24.9 \pm 2 \mathrm{~N}$ for the TTA knee (TABLE 1).

The PT force values at $90^{\circ}$ in the intact and ACL-deficient knee were very similar. ACL-deficient knee was slightly lower than the intact knee, except knee number 5 , which only increased by $7.2 \%$. But the values for the TTA knee decreased by approximately $20 \%$ compared to the healthy knee for specimens 1, 2 and 3. Only knee No. 4 was slightly higher than the intact knee by $6.2 \%$. So TTA tend to diminish the patellar tendon strain. It was also observed 


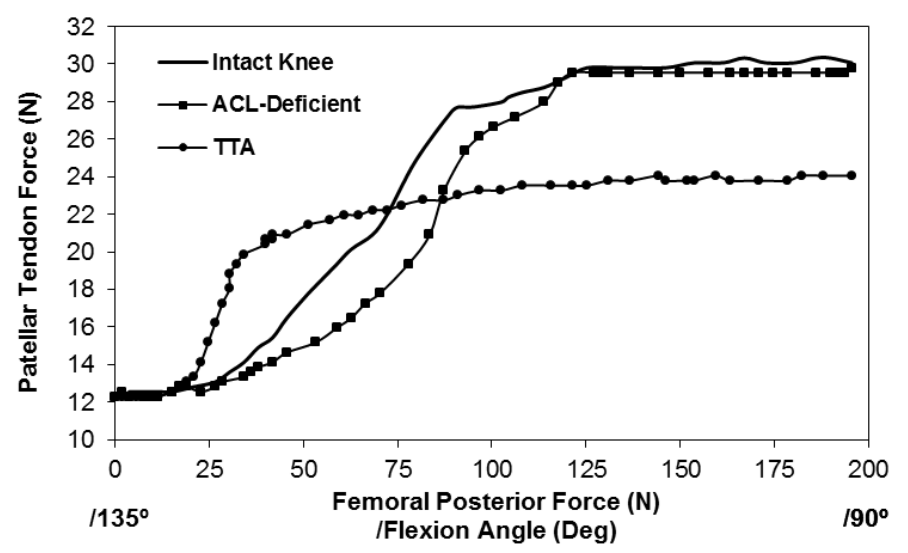

FIGURE 3. Patellar tendon vs. Femoral force (Newtons) curve in the intact, Anterior Cruciate Ligament - Deficient and Tibial Tuberosity Advancement knee from $135^{\circ}$ to $90^{\circ}$ flexion angles on knee 1

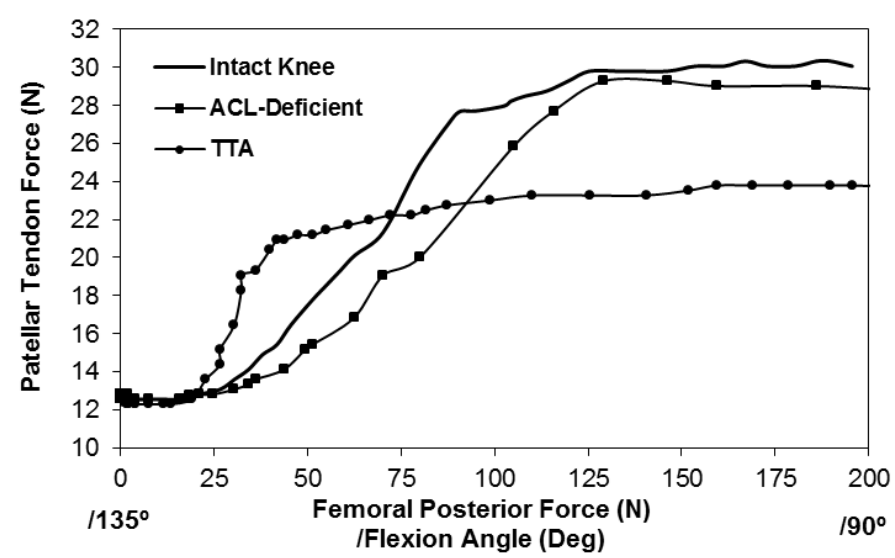

FIGURE 4. Patellar tendon vs. Femoral force (Newtons) curve in the intact, Anterior Cruciate Ligament - Deficient and Tibial Tuberosity Advancement knee from $135^{\circ}$ to $90^{\circ}$ flexion angles on knee 2

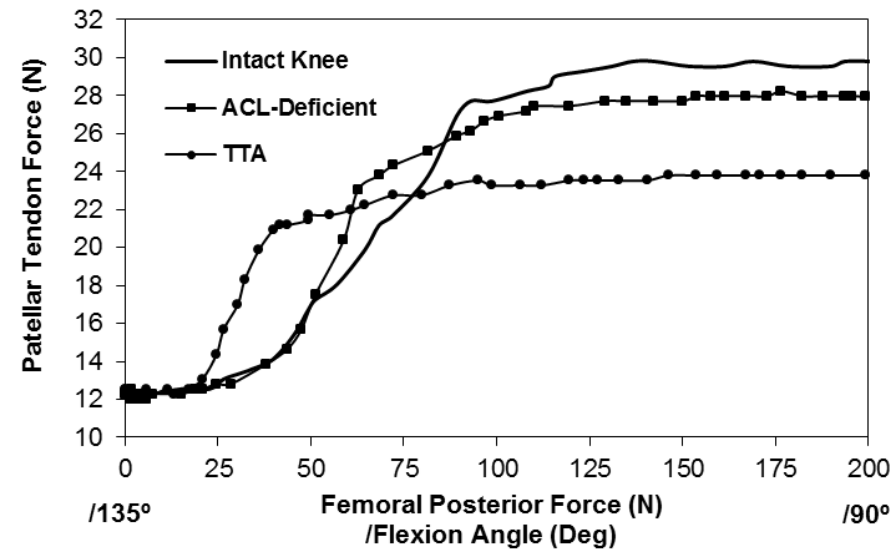

FIGURE 5. Patellar tendon vs. Femoral force (Newtons) curve in the intact, Anterior Cruciate Ligament - Deficient and Tibial Tuberosity Advancement knee from $135^{\circ}$ to $90^{\circ}$ flexion angles on knee 3

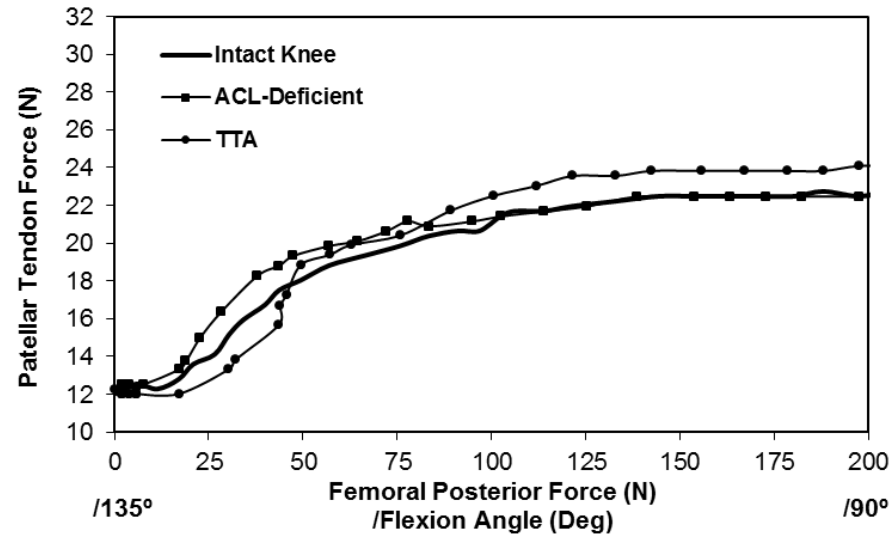

FIGURE 6. Patellar tendon vs. Femoral force (Newtons) curve in the intact, Anterior Cruciate Ligament - Deficient and Tibial Tuberosity Advancement knee from $135^{\circ}$ to $90^{\circ}$ flexion angles on knee 4

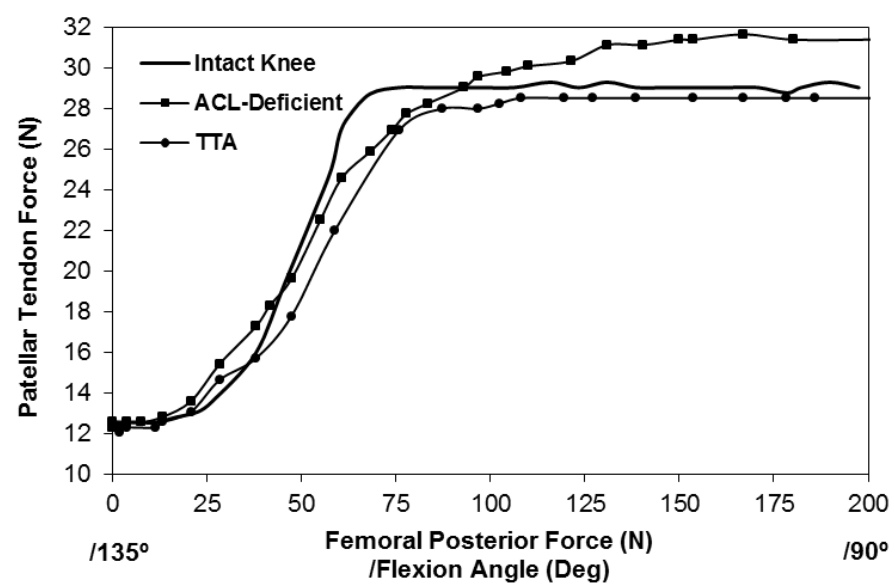

FIGURE 7. Patellar tendon vs. Femoral force (Newtons) curve in the intact, Anterior Cruciate Ligament - Deficient and Tibial Tuberosity Advancement knee from $135^{\circ}$ to $90^{\circ}$ flexion angles on knee 5

that the PT force increased faster in the TTA knee, so the pattern of knee flexion changed.

The purpose of the present study was to measure the PT force under caudal femoral force at joint angles of $135^{\circ}$ to $90^{\circ}$ degrees, and determine the effect of TTA on PT structure. Canine stifle joints were tested in vitro under muscle loads in different conditions: intact, ACL-deficient and TTA knees. Based on previous literature, it's expected that PT force increases with the knee in flexion, and that the TTA repair technique for ACL-deficient knees reduces the PT force during flexion.

One of the drawbacks of the study is that experimental models have large limitations to simulate actual conditions within the joint, and shear forces applied on the knee were of great magnitude. This is a reason why absolute measures may deviate from reality. But the comparison between specimens gives real results about PT behavior in the intact and pathological knee. On the other hand, there is a lack of PT force direct measurements in dogs. However, 
TABLE I

Data on Patellar tendon force (Newtons) in cadaver knees $(n=5)$ at $90^{\circ}$ flexion angle. ANOVA analysis

\begin{tabular}{cccccc}
\hline & \multirow{2}{*}{ Intact Knee } & \multicolumn{4}{c}{ Deviation relative to intact knee } \\
\cline { 3 - 6 } & & ACL-def. & TTA & ACL-def. (\%) & TTA (\%) \\
\hline knee 1 & 30.3 & 29.8 & 24.0 & -1.7 & -20.8 \\
knee 2 & 30.1 & 29.0 & 24.0 & -3.7 & -20.3 \\
knee 3 & 29.8 & 28.2 & 24.0 & -5.4 & -19.5 \\
knee 4 & 22.7 & 22.5 & 24.1 & -0.9 & 6.2 \\
knee 5 & 29.3 & 31.4 & 28.5 & 7.2 & -2.7 \\
Mean & 28.4 & 28.2 & 24.9 & & \\
Standard Deviation & 3.2 & 3.4 & 2.0 & & \\
Intact - ACL-def. - TTA knee & \multicolumn{5}{c}{$\mathrm{P}=0.15 ; \mathrm{R}^{2}=27.06 \%$} \\
Intact - TTA knee & $\mathrm{P}=0.07 ; \mathrm{R}^{2}=34.9 \%$ & & \\
\hline
\end{tabular}

ACL: Anterior Cruciate Ligament-deficient; TTA: Tibial Tuberosity Advancement

Nisell measured it in humans during the parallel squat. The QT force value at $90^{\circ}$ for males was $39 \mathrm{~N}$ [15]. The maximum QT force obtained in this study (without applying the reduction factor) is $36.4 \mathrm{~N}$ in the intact knee 1.

PT force increased under shear forces and with joint flexion angles from $135^{\circ}$ to $90^{\circ}$ in all specimens. Nisell observed that the PT force increased with flexion too from $120^{\circ}$ to $60^{\circ}$ joint angles, but especially the QT force, from $150^{\circ}$ to $90^{\circ}$ flexion angles [15]. When flexion occurs, the lever arm of the PT diminishes, so the muscle has to transfer greater forces to the tendons to maintain the same knee moment. This lever arm reduction was observed in a 3D finite element model of the entire knee joint [17]. They investigated the effect of $1.25-\mathrm{cm}$ and $2.5-\mathrm{cm}$ tubercle elevations under quadriceps and hamstrings loads at joint angles up to $90^{\circ}$. They found that the lever arm diminished while PF contact forces increased with the flexion angles.

The PT force in the ACL-deficient knee is slightly lower than in the intact knee in all specimens except No. 5, where it increases by $7.2 \%$. So the ACL-deficient knee doesn't affect the PT force.

In the TTA knee the PT force diminishes in all specimens by about $20 \%$ compared to the intact knee, except in No. 4, in which it only increases by $6.2 \%$. According to Maquet [10] advancement of the tibial tuberosity decreases quadriceps activation. This could be explained because the lever arm increases with the advancement of the tibial tubercle, so if the moment increases, the PT force will decrease to maintain the same knee joint moment. Shirazi-Adl and Mesfar [17] with their finite model observed the same, the lever arm increased slightly with the tuberosity advancement.

On the other hand, the curves show that the TTA knee behavior is unstable. The PT force is gradually increased in the intact and ACL-deficient knees, but the operated knee undergoes a shift at baseline in specimens 1,2 and 3. It seems that the TTA knee flexes faster than the intact knee. This could be explained because TTA surgery changes the relative contact point between femur and tibia. This could make flexion - which occurs naturally in the trials-, occur faster. The drawer between the advanced portion of the tuberosity and the tibia tends to displace the latter in the caudal direction. This could imply a change in the relative position between the joint surfaces, so the tibio-femoral contact point would move anteriorly on the tibial plateau. Due to the tibial plateau sloping in caudal direction, a greater rolling motion between the surfaces could occur. Nisell found that the tibio-femoral contact point moved caudaly on the tibial plateau when the knee was flexed [14]. This would have consequences in the normal knee kinematic patterns. In fact, Shirazi and Mesfar found that biomechanics of the tibiofemoral joint were significantly influenced by tibial tubercle elevation. The caudal cruciate ligament and tibiofemoral contact forces at larger flexion angles considerably increased [17].

\section{CONCLUSIONS}

From the experimental results it follows that PT force increases under femoral caudal force from $135^{\circ}$ to $90^{\circ}$ flexion angles, and that the force diminishes in canine stifle joints with TTA under muscle loads. The PT force in three out of five knees with TTA decreased by $20 \%$ versus the intact knee, and other knees had similar values to the intact. The current study suggests that the TTA technique for repairing canine ACL-deficient knees generates a loosening of the PT force.

A shift in the normal knee kinematic patterns has been observed in the TTA knee. The PT force increases faster in the operated knee because of a shift in the pattern of knee flexion. It is possible that the contact point between the joint surfaces would move anteriorly on the tibial plateau after the surgery. As a result, the biomechanics of the entire knee could be influenced by a technique applied in only a portion of it. Current results further emphasize the need for an integral view of the entire joint in management of disorders, and long-term follow-up clinical studies are needed. 


\section{BIBLIOGRAPHIC REFERENCES}

[1] APELT, D; KOWALESKI, MP; BOUDRIEAU, RJ. Effect of tibial tuberosity advancement on cranial tibial subluxation in canine cranial cruciate-deficient stifle joints: an in vitro experimental study. Vet. Surg. 36: 170-7. 2007.

[2] DECAMP, CE; SOUTASLITTLE, RW; HAUPTMAN, J; OLIVIER, B; BRADEN, T; WALTON, A. Kinematic Gait Analysis of the Trot in Healthy Greyhounds. Am. J. Vet. Res. 54: 627-34. 1993.

[3] HAYASHI, K; MANLEY, PA; MUIR, P. Cranial cruciate ligament pathophysiology in dogs with cruciate disease: A review. J. Am. Anim. Hosp. Asso. 40: 385-90. 2004

[4] HOFFMANN, DE; KOWALESKI, MP; JOHNSON, KA; EVANS, $\mathrm{RB}$. In vitro biomechanical evaluation of the canine $\mathrm{CrCL}$ deficient stifle with varying angles of stifle joint flexion and axial loads after TTA. Proceedings $18^{\text {th }}$ Annual Scientific Meeting of the European College of Veterinary Surgeons. Nantes, July 2-4, France. Pp 557-559. 2009

[5] HOFFMANN, DE; KOWALESKI, MP; JOHNSON, KA; EVANS, RB; BOUDRIEAU, RJ. Ex Vivo Biomechanical Evaluation of the Canine Cranial Cruciate Ligament-Deficient Stifle with Varying Angles of Stifle Joint Flexion and Axial loads after Tibial Tuberosity Advancement. Vet. Surg. 40: 311-20. 2011.

[6] HOTTINGER, HA; DECAMP, CE; OLIVIER, NB; HAUPTMAN, JG; SOUTASLITTLE, RW. Noninvasive kinematic analysis of the walk in healthy large-breed dogs. Am. J. Vet. Res. 57: 381-388. 1996.

[7] JERRAM, RM; WALKER, AM. Cranial cruciate ligament injury in the dog: pathophysiology, diagnosis and treatment. N. Z. Vet. J. 51: 149-158. 2003.

[8] KIM, SE; POZZI, A; BANKS, SA; CONRAD, BP; LEWIS, DD. Effect of Tibial Tuberosity Advancement on Femorotibial Contact Mechanics and Stifle Kinematics. Vet. Surg. 38: 33-39. 2009.

[9] KIPFER, NM; TEPIC, S; DAMUR, DM; GUERRERO, I; HAESSIG, M; MONTAVON, PM. Effect of tibial tuberosity advancement on femorotibial shear in cranial cruciate-deficient stifles an in vitro study. Vet. Comp. Orthop. Traumatol. 21: 385-390. 2008 .
[10] MAQUET, P. Advancement of Tibial Tuberosity. Clin. Orthop. Relat. Res. 115: 225-230. 1976.

[11] MILLER, JM; SHIRES, PK; LANZ, OI; MARTIN, RA; GRANT, JW. Effect of $9 \mathrm{~mm}$ tibial tuberosity advancement on cranial tibial translation in the canine cranial cruciate ligament-deficient stifle. Vet. Surg. 36: 335-340. 2007.

[12] MONTAVON, PM; DAMUR, DM; TEPIC, S. Advancement of the tibial tuberosity for the treatment of cranial cruciate deficient canine stifle. Proceedings $1^{\text {st }}$ World Orthopaedic Veterinary Congress. Munich, 09/5-8, Germany. Pp 152. 2002.

[13] MONTAVON, PM; DAMUR, DM; TEPIC, S. Tibial tuberosity advancement (TTA) for the treatment of cranial cruciate disease in dogs, evidences, technique and initial clinical results. Proceedings $12^{\text {th }}$ ESVOT Congress. Munich, 09/1012, Germany. Pp 254-255. 2004.

[14] NISELL, R. Mechanics of the Knee - a Study of Joint and Muscle Load with Clinical-Applications. Acta. Orthop. Scand. 56: 1-42. 1985.

[15] SCHAEFER, SL; DECAMP, CE; HAUPTMAN, JG; WALTON, A. Kinematic gait analysis of hind limb symmetry in dogs at the trot. Am. J. Vet. Res. 59: 680-685. 1998.

[16] SHAHAR, R; BANKS-SILLS, L. A quasi-static three-dimensional, mathematical, three-body segment model of the canine knee. J. Biomech. 37: 1849-1859. 2004.

[17] SHIRAZI-ADL, A; MESFAR, W. Effect of tibial tubercle elevation on biomechanics of the entire knee joint under muscle loads. Clin. Biomech. 22: 344-351. 2007.

[18] TEPIC, S; DAMUR, DM; MONTAVON, PM. Biomechanics of the stifle joint. Proceedings $1^{\text {st }}$ World Orthopaedic Veterinary Congress. Munich, 09/5-8, Germany. Pp 189-190. 2002. 